\title{
Detection and quantification of microRNA in cerebral microdialysate
}

\author{
Søren Bache ${ }^{1,3^{*}}$, Rune Rasmussen², Maria Rossing ${ }^{3}$, Niels Risør Hammer ${ }^{1}$, Marianne Juhler², Lennart Friis-Hansen ${ }^{3,4}$, \\ Finn Cilius Nielsen ${ }^{3}$ and Kirsten Møller ${ }^{1}$
}

\begin{abstract}
Background: Secondary brain injury accounts for a major part of the morbidity and mortality in patients with spontaneous aneurysmal subarachnoid hemorrhage $(\mathrm{SAH})$, but the pathogenesis and pathophysiology remain controversial. MicroRNAs (miRNAs) are important posttranscriptional regulators of complementary mRNA targets and have been implicated in the pathophysiology of other types of acute brain injury. Cerebral microdialysis is a promising tool to investigate these mechanisms. We hypothesized that miRNAs would be present in human cerebral microdialysate.
\end{abstract}

Methods: RNA was extracted and miRNA profiles were established using high throughput real-time quantification PCR on the following material: 1) Microdialysate sampled in vitro from A) a solution of total RNA extracted from human brain, B) cerebrospinal fluid (CSF) from a neurologically healthy patient, and C) a patient with SAH; and 2) cerebral microdialysate and CSF sampled in vivo from two patients with SAH. MiRNAs were categorized according to their relative recovery (RR) and a pathway analysis was performed for miRNAs exhibiting a high RR in vivo.

Results: Seventy-one of the 160 miRNAs detected in CSF were also found in in vivo microdialysate from SAH patients. Furthermore specific miRNAs consistently exhibited either a high or low RR in both in vitro and in vivo microdialysate. Analysis of repeatability showed lower analytical variation in microdialysate than in CSF.

Conclusions: MiRNAs are detectable in cerebral microdialysate; a large group of miRNAs consistently showed a high RR in cerebral microdialysate. Measurement of cerebral interstitial miRNA concentrations may aid in the investigation of secondary brain injury in neurocritical conditions.

\section{Background}

Secondary brain injury accounts for a major part of the morbidity and mortality in patients with spontaneous aneurysmal subarachnoid hemorrhage (SAH) [1]. However, the cellular mechanisms leading to this complication are incompletely understood. Cerebral microdialysis, in which a catheter lined by a semipermeable membrane is perfused in order to sample fluid containing substances from the cerebral interstitial space, is a promising tool to investigate these mechanisms. Even so, the substances measured in the clinical setting today are largely limited

\footnotetext{
* Correspondence: bache@dadlnet.dk

'Department of Neuroanaesthesiology, The Neuroscience Centre,

Copenhagen University Hospital, Copenhagen, Denmark

${ }^{3}$ Centre for Genomic Medicine, The Diagnostic Centre, Rigshospitalet,

Copenhagen University Hospital, Copenhagen, Denmark

Full list of author information is available at the end of the article
}

to products of metabolism, such as glucose, lactate and pyruvate $[2,3]$.

MicroRNAs (miRNAs) are a group of 22 nucleotides long, non-coding RNA molecules involved in posttranscriptional regulation of complementary mRNA targets [4]. MiRNAs are well conserved in animals and are highly tissue specific. They act intracellularly, are transported outside the cells in exosomes and may exist in stable forms in body fluids [5]. Specific miRNAs are implicated experimentally in neuronal apoptosis following acute cerebral ischemia [6,7] intracerebral hemorrhage [8] and are associated clinically with the severity of traumatic brain injury [9]. Measuring the interstitial concentration of specific miRNAs may provide valuable information on tissue function. We hypothesized that miRNAs are present in human cerebral interstitial fluid, are consistently filtered through the membrane of a cerebral microdialysis catheter, and hence, can also be detected 
in human cerebral microdialysate with low analytical variation. Thus, we aimed to develop and validate a method to measure miRNA expression in cerebral microdialysate.

\section{Methods}

The protocol for this study was approved by the Danish Regional Scientific Ethics Committee of the Capital Region \# H-3-2013-009 and registered on clinicaltrials.gov \# NCT01791257. According to Danish law, the samples described below were obtained following informed consent by either the patient or by their next of kin and their general practitioner.

\section{Samples}

In order to compare RNA in undialyzed samples to samples that had undergone microdialysis, human cerebral RNA, CSF and cerebral microdialysate was obtained and processed as follows:

1. Samples for in vitro studies:

A. Total RNA extracted from human brain (Clontech Laboratories, Inc., California, USA) was stored at $-80^{\circ} \mathrm{C}$ until use. Upon thawing, RNA was reconstituted in "CNS perfusion fluid" (MDialysis, Stockholm, Sweden) for a final volume of $3 \mathrm{ml}$ and concentration of $21 \mu \mathrm{g} / \mathrm{ml}$ and divided into three aliquots. Samples underwent in vitro microdialysis as described below, using a catheter pore size of 20 or $100 \mathrm{kDa}$, or no microdialysis. The resulting samples were named "RNA MD20", "RNA MD 100 ", and "RNA REF".

B. CSF (2 ml) was aspirated using a $27 \mathrm{G}$ pencil point spinal needle prior to injection of local anesthetic in a neurologically healthy patient undergoing spinal anesthesia (hereafter referred to as a "healthy control patient"). The CSF was spun at $500 \mathrm{~g}$ for 10 minutes; the supernatant was stored at $-80^{\circ} \mathrm{C}$ until use. Upon thawing and division into two aliquots, one sample underwent in vitro microdialysis as described below using a catheter pore size of $100 \mathrm{kDa}$, whereas the other sample was left undialyzed. The resulting samples were named "H MD100" and "H REF".

C. CSF (5 ml) was sampled from the external ventricular drainage system placed in a patient with SAH (patient 1) on day 6 after ictus. The CSF was spun at $500 \mathrm{~g}$ for 10 minutes; the supernatant was stored at $-80^{\circ} \mathrm{C}$ until use. Upon thawing and division into five aliquots, four of these underwent in vitro microdialysis as described below, using four identical catheters with a pore size of $20 \mathrm{kDa}$, resulting in samples named "SAH1 MD20A through D", whereas the remaining aliquot served as four undialyzed reference samples, named "SAH1 REFA through D".

Figure 1A depicts the in vitro study setup.

2. CSF and microdialysate samples for in vivo study: In two patients with SAH treated with external ventricular drainage and undergoing bedside microdialysis on clinical indications (patients 2 and 3), CSF from the drainage system as well as microdialysate from an intracerebral microdialysis catheter (Figure 1B) containing a $20 \mathrm{kDa}$ membrane were collected on Day 3 and 9. This resulted in eight samples named "SAH2D3 MD20", "SAH3D3 MD20", "SAH2D9 MD20", "SAH3D9 MD20", "SAH2D3 REF", "SAH3D3 REF", "SAH2D9 REF", and "SAH3D9 REF".

Details regarding in vitro and in vivo samples are shown in Table 1 . CSF samples were spun at $500 \mathrm{~g}$ for

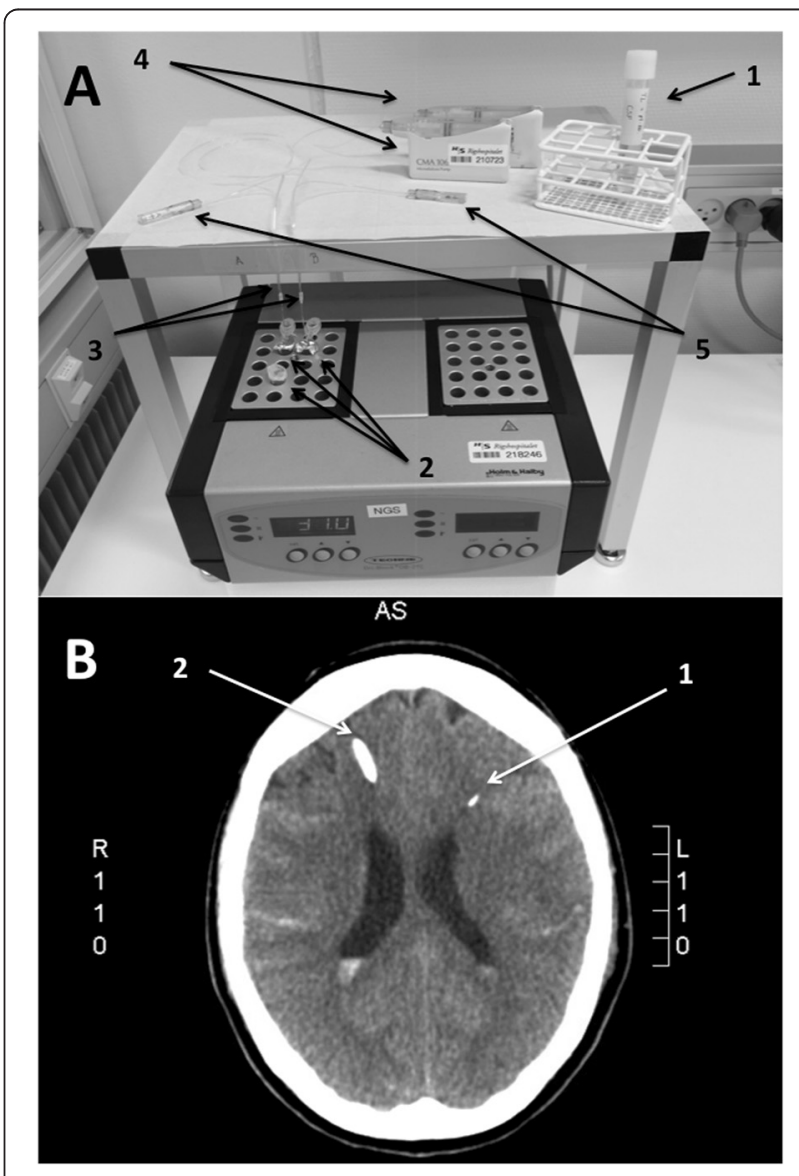

Figure 1 Materials and methods. A: Setup for in vitro microdialysis. 1, cerebrospinal fluid sample; 2 , identical aliquots of the cerebrospinal fluid; 3 , two microdialysis catheters with a membrane length of $10 \mathrm{~mm}$ and a $20 \mathrm{kDa}$ cut-off; 4, perfusion pumps; 5, vials gathering samples of microdialysis fluid. B: Computed tomography scan from SAH patient 3. 1 , a microdialysis catheter placed in the left frontal lobe; 2 , part of the external drain passing through the brain. 
Table 1 Schematic overview of pre-analytical and analytical setup

\begin{tabular}{|c|c|c|c|c|c|c|}
\hline Sample number & Sample name & Source & Micro-dialysis & $\begin{array}{l}\text { Catheter pore } \\
\text { size }\end{array}$ & $\begin{array}{l}\text { Perfusion fluid } \\
\text { for microdialysis }\end{array}$ & $\begin{array}{l}\text { qPCR - number } \\
\text { of miRNA }\end{array}$ \\
\hline 1 & RNA MD20 & Human brain, total RNA & In vitro & $20 \mathrm{kDa}$ & CNS & 377 \\
\hline 2 & RNA MD100 & Human brain, total RNA & In vitro & $100 \mathrm{kDa}$ & HA 3.5\% & 377 \\
\hline 3 & RNA REF & Human brain, total RNA & None & NA & NA & 377 \\
\hline 4 & H MD100 & Healthy human, LP-CSF & In vitro & $100 \mathrm{kDa}$ & HA 3.5\% & 377 \\
\hline 5 & H REF & Healthy human, LP-CSF & None & NA & NA & 377 \\
\hline 6 & SAH1 MD20A & SAH patient 1, EVD-CSF & In vitro & $20 \mathrm{kDa}$ & CNS & 754 \\
\hline 7 & SAH1 MD20B & SAH patient 1, EVD-CSF & In vitro & $20 \mathrm{kDa}$ & CNS & 754 \\
\hline 8 & SAH1 MD2OC & SAH patient 1, EVD-CSF & In vitro & $20 \mathrm{kDa}$ & CNS & 754 \\
\hline 9 & SAH1 MD20D & SAH patient 1, EVD-CSF & In vitro & $20 \mathrm{kDa}$ & CNS & 754 \\
\hline 10 & SAH1 REFA & SAH patient 1, EVD-CSF & None & NA & NA & 754 \\
\hline 11 & SAH1 REFB & SAH patient 1, EVD-CSF & None & NA & NA & 754 \\
\hline 12 & SAH1 REFC & SAH patient 1, EVD-CSF & None & NA & NA & 754 \\
\hline 13 & SAH1 REFD & SAH patient 1, EVD-CSF & None & NA & NA & 754 \\
\hline 14 & SAH2D3 MD2O & SAH patient 2, in vivo MD, day 3 & In vivo & $20 \mathrm{kDa}$ & CNS & 377 \\
\hline 15 & SAH3D3 MD20 & SAH patient 3 , in vivo MD, day 3 & In vivo & $20 \mathrm{kDa}$ & CNS & 377 \\
\hline 16 & SAH2D9 MD20 & SAH patient 2, in vivo MD, day 9 & In vivo & $20 \mathrm{kDa}$ & CNS & 377 \\
\hline 17 & SAH3D9 MD20 & SAH patient 3, in vivo MD, day 9 & In vivo & $20 \mathrm{kDa}$ & CNS & 377 \\
\hline 18 & SAH2D3 REF & SAH patient 2, EVD-CSF, day 3 & None & NA & NA & 377 \\
\hline 19 & SAH3D3 REF & SAH patient 3, EVD-CSF, day 3 & None & NA & NA & 377 \\
\hline 20 & SAH2D9 REF & SAH patient 2, EVD-CSF, day 9 & None & NA & NA & 377 \\
\hline 21 & SAH3D9 REF & SAH patient 3, EVD-CSF, day 9 & None & NA & NA & 377 \\
\hline
\end{tabular}

qPCR, real-time polymerase chain reaction; miRNA, microRNA; MD, microdialysis; CNS, "Central nervous system perfusion fluid" (Mdialysis); HA, human albumin (CLS Behring); ref, reference; NA, not applied; LP-CSF, cerebrospinal fluid obtained by lumbar puncture; SAH, spontaneous aneurysmal subarachnoid hemorrhage; EVD-CSF = cerebrospinal fluid obtained from external ventricular drain.

10 minutes; the supernatant was stored at $-80^{\circ} \mathrm{C}$ until use. Microdialysate was stored at $-80^{\circ} \mathrm{C}$ until use.

\section{Microdialysis}

In vivo and in vitro microdialysis was carried out using catheters (MDialysis, Stockholm, Sweden) with membrane lengths of $10 \mathrm{~mm}$ and cut-off values of either $20 \mathrm{kDa}$ or $100 \mathrm{kDa}$ as outlined above and in Table 1. Catheters were perfused at $0.3 \mu \mathrm{min}^{-1}$ with a CMA106 Microdialysis Pump (MDialysis) using "CNS perfusion fluid" (MDialysis) for $20 \mathrm{kDa}$ membranes; for $100 \mathrm{kDa}$ membranes, human albumin (3.5\%; CLS Behring, Copenhagen, Denmark) was chosen because we observed fluid leakage across the $100 \mathrm{kDa}$ membrane using "CNS perfusion fluid" as reported by others [10]. Vials for sampling were replaced every two hours, for a resulting volume of $36 \mu$ per vial; for subsequent RNA isolation, no in vivo vials sampled within two hours of catheter insertion were used, the content of eight successive vials $(288 \mu \mathrm{l})$ were pooled for each sample, and $200 \mu \mathrm{l}$ was transferred for further processing as described below.

The temperature for all in vitro procedures was set at $37^{\circ} \mathrm{C}$ to resemble in vivo microdialysis. Undialyzed reference samples were kept at $37^{\circ} \mathrm{C}$ for two hours and stored at $-80^{\circ} \mathrm{C}$ until use.

\section{RNA isolation}

Total RNA was isolated from $200 \mu$ l of each sample according to the manufacturer's protocol (Total RNA isolation kit, Appendix B, Norgen Biotek, Thorold, Canada), including the addition of beta-mercaptoethanol to the lysis solution.

\section{Real-time quantification}

For each sample, a fixed volume of $6 \mu$ l eluted RNA sample was mixed on ice with $9 \mu \mathrm{l}$ of a reverse transcription reaction containing $1.6 \mu \mathrm{l}$ of 10X RT buffer, $1.8 \mu \mathrm{l}$ of $\mathrm{MgCl} 2,0.2 \mu \mathrm{l}$ of RNase-inhibitor $(20 \mathrm{U} / \mu \mathrm{l}), 0.4 \mu \mathrm{l}$ of dNTPs with dTTP $(100 \mathrm{mM}), 3.0 \mu \mathrm{l}$ of Multiscribe Reverse Transcriptase $(50 \mathrm{U} / \mu \mathrm{l}), 1.6 \mu \mathrm{l}$ of Megaplex RT primers $(\mathrm{x} 10)$ and $0.4 \mu \mathrm{l}$ of nuclease free water. Reverse transcription was performed using 40 cycles of $16^{\circ} \mathrm{C}$, $2 \mathrm{~min} ; 42^{\circ} \mathrm{C}, 1 \mathrm{~min}$ and $50^{\circ} \mathrm{C}, 1 \mathrm{sec}$ followed by $85^{\circ} \mathrm{C}$ for 5 min and hold at $4^{\circ} \mathrm{C}$. For each sample, a preamplification reaction comprising $62.5 \mu \mathrm{l}$ of TaqMan PreAmp Master Mix (2X), $12.5 \mu \mathrm{l}$ of Megaplex PreAmp Primers 
(10X), $37.5 \mu \mathrm{l}$ of nuclease-free water and $12.5 \mu \mathrm{l}$ of RT product were mixed on ice. After $10 \mathrm{~min}$ at $95^{\circ} \mathrm{C}, 2 \mathrm{~min}$ at $55^{\circ} \mathrm{C}$ and $2 \mathrm{~min}$ at $72^{\circ} \mathrm{C}$ the cDNA was subjected to 12 cycles of $15 \mathrm{sec}$ at $95^{\circ} \mathrm{C}$ and $4 \mathrm{~min}$ at $60^{\circ} \mathrm{C}$ followed by $10 \mathrm{~min}$ at $99,9^{\circ} \mathrm{C}$ and hold at $4^{\circ} \mathrm{C}$. The preamplified product was diluted with $375 \mu \mathrm{l}$ of $0.1 \mathrm{TE}$ buffer. For each sample, $450 \mu \mathrm{l}$ of diluted preamplified product was mixed on ice with $450 \mu \mathrm{l}$ of TaqMan Fast Advanced Master Mix and $800 \mu \mathrm{l}$ loaded on a TaqMan Human MicroRNA Array Card. qRT-PCR was performed using the Viia 7 real-time PCR system (Applied Biosystems, Foster City, CA). Samples 6-13 were screened for 754 specific miRNAs using Human Pools A v.2.1 and B v.3.0. The remaining samples were screened for 377 specific miRNAs using Human Pools A v.2.1. Reagents and array cards were all purchased from Invitrogen, Carlsbad, CA.

\section{Normalization \& statistical analysis}

Cycle threshold was set to 0.1 and baseline between 3 and 15 for all targets. Cycle quantification $(\mathrm{Cq})$ values correlate inversely with concentration. A Cq value $>32$ were considered below the detection limit and were discarded and the mean normalization strategy [11] was applied. To compare measurement variability in microdialysate and CSF, SDs were compared using the paired Student's $t$ test. $\mathrm{P}<0.05$ was considered significant.

MiRNAs were categorized according to their relative recovery (RR) in microdialysate as exhibiting a "high" or "low" RR according to the criteria described in Table 2; miRNAs, for which this characterization was not possible, were classified as having an "indeterminate" RR. Please refer to Table 2 for a detailed description of the criteria for categorization.

\section{MiRNA target pathway analysis}

MiRNAs exhibiting a high RR in vivo were uploaded to the Ingenuity Pathway Analysis software (Qiagen, Venlo, Holland) and a search of putative mRNA targets was performed which was limited to "experimentally observed". Target mRNAs were subsequently employed in a gene set enrichment analysis in the $\mathrm{C} 2$ Reactome Molecular Signature Database v4.0 (www.broadinstitute.org). A similar analysis was performed with a gene set of mRNAs that have been reported by others to be differentially expressed between the brain tissue from the perihematomal region and the contralateral region from patients suffering from intracerebral hemorrhage [12].

\section{Results}

\section{MiRNA profiles of CSF and microdialysate}

In the sample of total RNA extracted from human brain tissue, 205 out of 377 tested miRNAs (60\%) were detected in the undialyzed reference sample; of these 205 miRNAs, 171 (83\%) were detected after in vitro microdialysis using a membrane cutoff of $20 \mathrm{kDa}$, and 84 (41\%) were detected after microdialysis using a $100 \mathrm{kDa}$ membrane.

In the healthy control patient, 114 of 377 tested miRNAs (34\%) were detected in undialyzed CSF; of these 114 miRNAs, 71 (62\%) were detected after in vitro microdialysis using a $100 \mathrm{kDa}$ membrane.

In the three patients with $\mathrm{SAH}$, samples from patient 1 were screened for 754 specific miRNAs, whereas samples from patients 2 and 3 were screened for the presence of 377 miRNAs. In patient 1, 203 miRNAs were detected in all four identical samples of CSF, of which 112 (55\%) were detected in all four corresponding microdialysate samples obtained in vitro. In patients 2 and 3, 160 miRNAs were detected in all four samples of CSF, and $71(44 \%)$ of these were detected in all four samples of microdialysate obtained in vivo. Conversely, all miRNAs identified in all four in vivo samples of microdialysate were also identified in in vivo CSF. All mean normalized Cq values of specific miRNAs can be found in Additional file 1.

\section{Selective passage of microdialysis membrane}

The microdialysate relative recovery (RR) of different miRNAs varied considerably in the in vitro studies. However, the RR of each specific miRNA was consistent

Table 2 Criteria for categorization

\begin{tabular}{|c|c|c|c|}
\hline Groups & Inclusion criteria for each specific miRNA & Based on samples & miRNA targets \\
\hline \multirow[t]{2}{*}{ High RR } & \multirow{2}{*}{$\begin{array}{l}\text { in vitro } \mathrm{Cq}_{\text {mean }} \mathrm{CSF}-\mathrm{Cq}_{\text {mean } \mathrm{MD}}< \pm 2 \text { and in vitro } \mathrm{SD}_{\mathrm{CSF}} \\
\text { and } \mathrm{SD}_{\mathrm{MD}} \text { both }<1\end{array}$} & $6-13$ & \multirow[t]{2}{*}{63} \\
\hline & & $6-13$ & \\
\hline \multirow[t]{2}{*}{ Low RR } & \multirow[t]{2}{*}{ in vitro $\mathrm{Cq}_{\text {mean } \mathrm{MD}}-\mathrm{Cq}_{\mathrm{mean}} \mathrm{CSF}>4$ and in vitro $\mathrm{SD}_{\mathrm{CSF}}<1$} & $6-13$ & \multirow[t]{2}{*}{53} \\
\hline & & $6-13$ & \\
\hline Indetermined RR & Criteria not fulfilled & $6-13$ & 173 \\
\hline Not present & Not detected in any samples & $6-13$ & 465 \\
\hline
\end{tabular}

Criteria for categorization of 754 screened miRNAs according to their relative recovery in microdialysate from a catheter with a membrane cut-off value of $20 \mathrm{kDa}$. $\mathrm{RR}$, relative recovery; $\mathrm{Cq}_{\text {mean }} \mathrm{CSF}$, mean cycle quantification of the specific miRNA in sample 10-13, Table $1 ; \mathrm{Cq}_{\text {mean }} \mathrm{MD}$, mean cycle quantification of the specific miRNA in sample 6-9, Table 1; SD CSF, $_{\text {, standard deviation of cycle quantification of the specific miRNA in sample 10-13, Table 1; SD }}$ MD, standard deviation of cycle quantification of the specific miRNA in sample 6-9, Table 1. 
in the three in vitro studies. Of the 754 specific miRNAs screened, 63 were categorized as exhibiting a high RR, 53 as exhibiting a low RR, and 173 as exhibiting an indeterminate RR. The 465 remaining miRNAs were not identified in the reference material and therefore could not be evaluated. These characteristic abilities to pass through the membrane were reproduced in the in vivo studies. Figures 2 and 3 show Cq values of representative miRNAs from the group with a high $R R$ and the one with a low RR and illustrates the reproducibility from in vitro to in vivo studies. The complete distribution of all 754 miRNAs in the four groups is shown in Additional file 2.

\section{Repeatability}

In order to investigate analytical variation, we compared standard deviations of $\mathrm{Cq}$ values in microdialysate and CSF from patient 1 (SAH1 MD20A through D compared to samples SAH1 REFA through D, Table 1). Since miRNAs at low concentrations increase analytical variation in qRT-PCR markedly, including miRNAs with a low or indeterminate $R R$ would lead to an overestimation of the analytical variation contributed by microdialysate. Therefore, analysis focused on the group of $63 \mathrm{miR}$ NAs showing a high RR; the average SD of Cq values in microdialysate was lower than that of CSF (SD for microdialysate, 0.37 (95\% CI, 0.33-0.42) vs. SD for CSF, 0.46 (95\% CI, 0.41-0.51) ( $\mathrm{p}=0.011)$.

\section{MiRNA target pathway analysis}

In order to obtain an overview of the possible biological significance of the 31 miRNAs exhibiting a high RR in microdialysate obtained in vivo, we performed a pathway analysis of putative target mRNAs. Transcripts were matched to the C2 Reactome in the Molecular Signature Database $\mathrm{v} 4.0$, and the 50 most significantly related reactomes (FDR q-value $\leq 1.02 \times 10^{-5}$ ) are listed in Additional file 3. Comparing these results to the 50 most significantly related reactomes $\left(\right.$ FDR $q$-value $\leq 4.64 \times 10^{-3}$ ) from a similar pathway analysis, based on a gene set of mRNAs differentially expressed between the brain tissue from the perihematomal region and the contralateral region from patients suffering from intracerebral hemorrhage, revealed an overlap of 13 reactomes (Additional file 3).

\section{Discussion}

We have shown that miRNAs, important regulators of cell function, can be detected in human cerebral microdialysate sampled in vivo. Our findings have three main implications. First, this method offers a new approach to test hypotheses related to the presence, regulation and roles of miRNAs in the brain of neurocritically ill patients. Secondly, in vivo microdialysis for the study of miRNA is not limited to brain tissue, but could likely be applied to many tissues. Finally, the membrane of a microdialysis catheter resembles a semi-permeable membrane, and the results provide information on the much-debated topic of the size and characteristics of the proposed forms of miRNA which may prevent their degradation by RNases [13].

Besides showing the presence of miRNAs in cerebral microdialysis fluid sampled in vivo, the in vitro part of this study demonstrated that 63 out of 754 screened miRNAs show a high RR when using a $20 \mathrm{kDa}$ microdialysis membrane. Of these 63 miRNAs, 34 were screened in the in vivo samples, and for 26 of these, a high RR was confirmed using the same criteria as for the in vitro study (Figure 2 - bottom). Of the remaining eight miRNAs, seven miRNAs came very close to meeting the criteria for a high RR; only one miRNA showed a markedly different expression pattern and variation. The reason for this outlying result is unknown, but could be due to both analytical imprecision or biological variation within samples. Nevertheless, the in vivo confirmation of the in vitro results shows consistency in the ability of each given miRNA to filter through the microdialysis membrane. Therefore, we recommend that future studies may include 62 of the 63 miRNAs meeting the criteria for a high RR, since their filtration fraction may be assumed to be stable as well.

The cut-offs for a given miRNA to be placed in the "high RR" group, an $\mathrm{SD}<1 \mathrm{Cq}$ and a microdialysate to CSF difference of $<2 \mathrm{Cq}$, was a compromise between increasing specificity by lowering both cut-offs and the challenge that each SD represents the qRT-PCR of one well from each of four array cards in order to allow for a wide miRNA-screening. This approach, however, means that the analytical variation cannot be reduced by running multiplicates (e.g.triplicates) of each miRNA. In our opinion, this may be a suitable approach when studying limited amounts of specific miRNAs of interest.

In order to compare samples obtained from different patients, at different time points, we estimated the analytical variation. For the 63 miRNAs showing a high RR, the average variability of expression values was significantly lower in microdialysate than in CSF. One explanation could be that microdialysis removes larger molecules, which interferes with downstream analysis or parts thereof (e.g. RNA extraction) in the undialyzed control samples. Nevertheless, the observation that microdialysis may not decrease, but in fact seems to increase, reproducibility of qRT-PCR, is important. Thus, microdialysis may provide a more accurate method than simple CSF sampling to monitor changes in cerebral miRNA expression over time and between patients and patient groups.

The above findings indicate that it may be possible to quantify the cerebral interstitial concentration of at least 


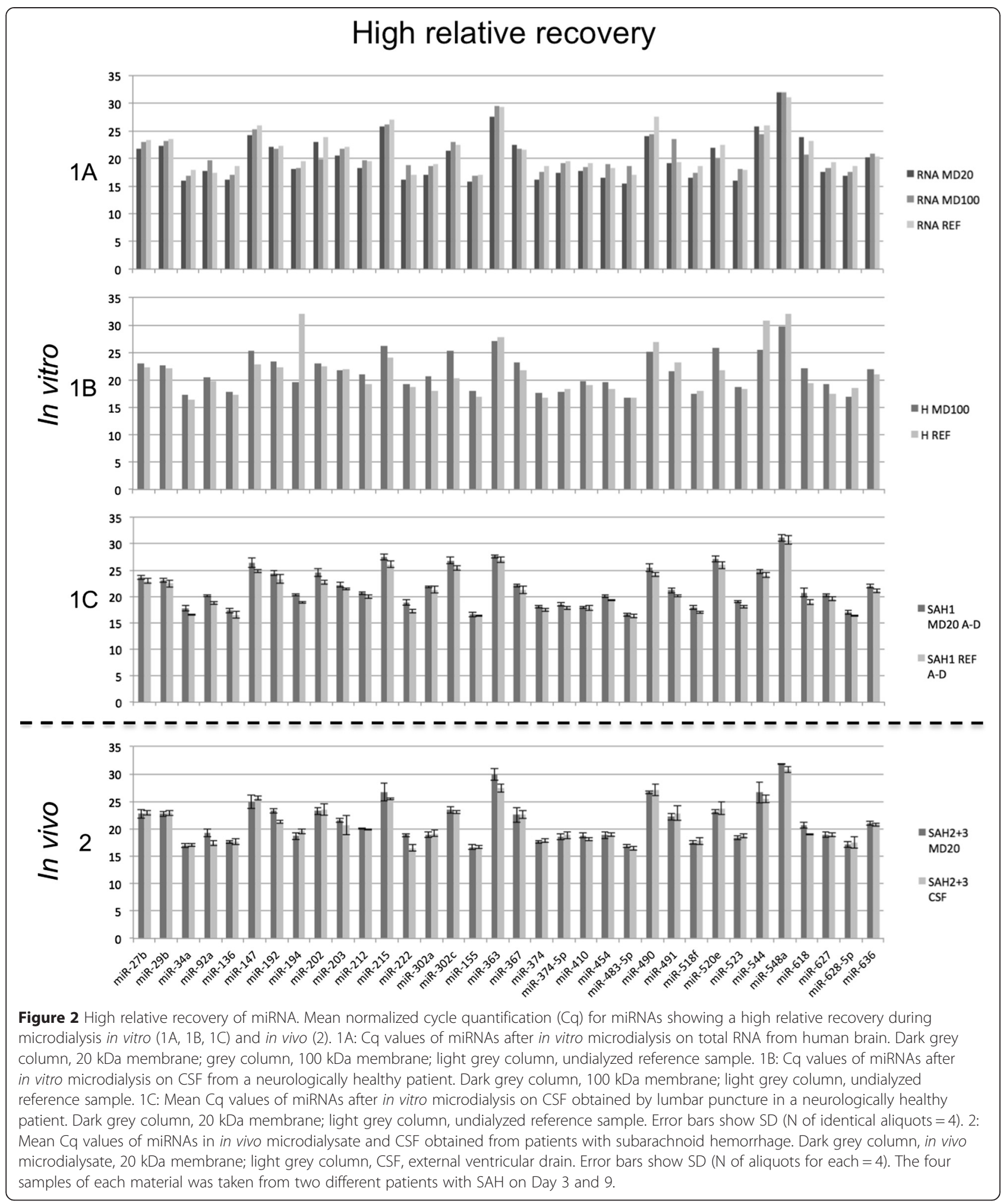

62 miRNAs in a clinical setting with acceptable precision. Additionally, some miRNAs with an indeterminate or low RR appear to show acceptable measurement accuracy, though this would require additional studies.
Finally, according to the experience in our laboratory, miRNAs may be quantified from as little as $25 \mu \mathrm{l}$ of microdialysate, i.e. much less than used in this study, with good reproducibility (data not shown), indicating 


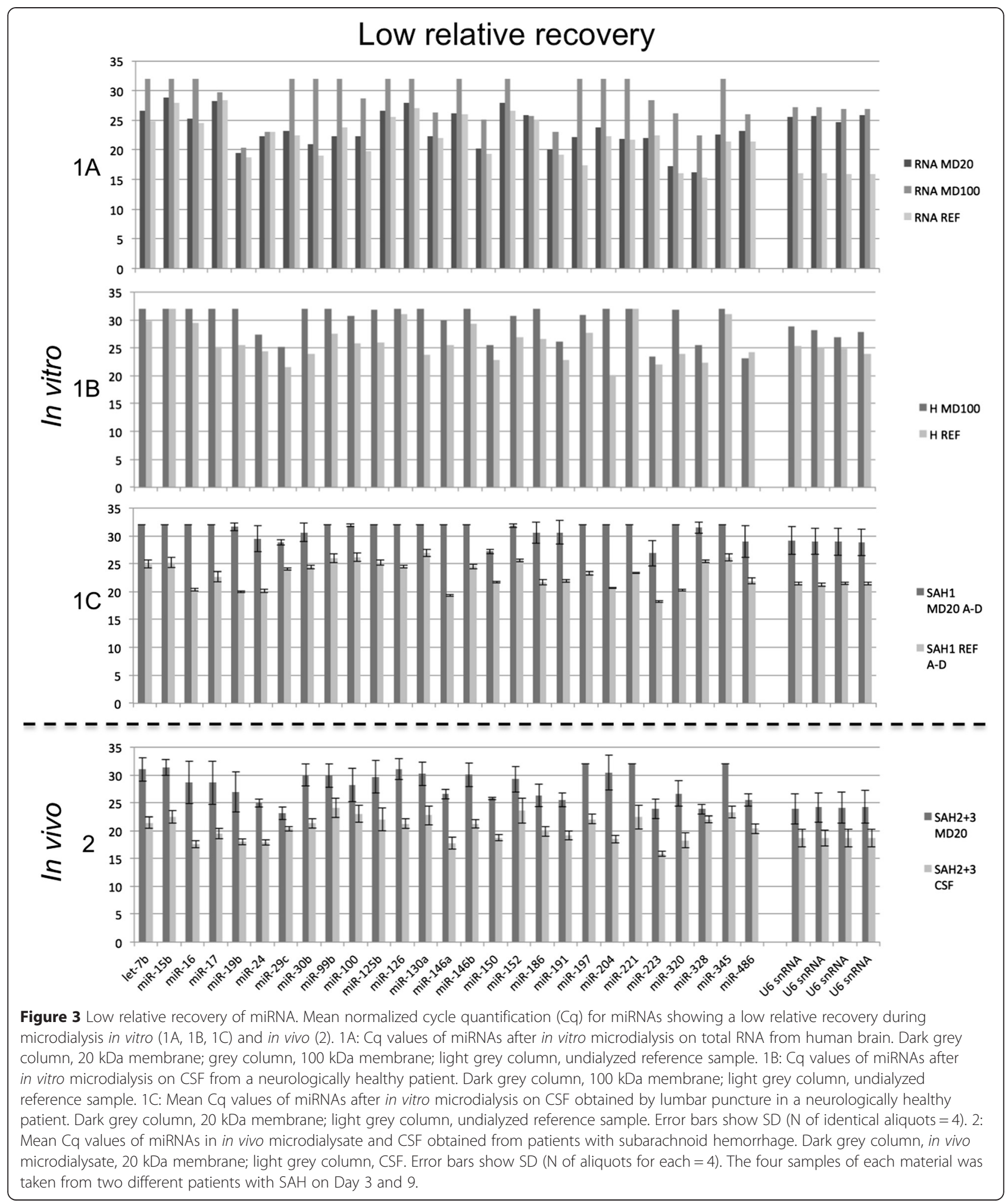

that continuous measurements with acceptable time resolution are possible in a clinical setting.

To our knowledge, this is the first time that in vivo microdialysis has been conducted in humans in order to sample miRNAs. For local changes in interstitial miRNA levels to be of importance, they need to reflect the intracellular levels. Accordingly, in vitro studies indicate that an energy-dependent equilibrium exists between the 
intracellular and extracellular compartments regarding miRNAs [14]. Furthermore, the miRNAs presented in Table 3 have previously been implicated in cerebral ischemia or inflammation. For instance, up-regulation of miR-29b in brain tissue following experimental transient middle cerebral artery occlusion, was found to inhibit Bcl2L2 gene expression resulting in increased neuronal cell death. In addition, inhibition of miR-29b increased Bcl2L2 gene expression and decreased neuronal cell death, indicating that miR-29b may be an important mediator of an adverse outcome in cerebral ischaemia [7]. In the present study, miR-29b showed a high RR in cerebral microdialysate. We suggest that changes in miR-29b may be monitored by microdialysis in humans in order to test the hypothesis raised in the study described above. Similarly, miR-34a and miR-155, which have been implicated experimentally in traumatic brain injury [15] and central nervous system inflammation following cerebral ischemia [16], both exhibited a high RR and therefore will be of great interest to monitor in similar patients. More generally, we compared results of pathway analyses of our data set of miRNAs exhibiting a high RR in vivo and a data set from patients with intracerebral hemorrhage. These analyses indicate that miRNAs exhibiting a high RR in vivo, may be implicated in the regulation of transcripts involved in among others hemostasis; axon guidance; signaling by nerve growth factor; adaptive immune system; platelet activation, signaling and aggregation; following intracerebral hemorrhage.

The array cards used for miRNA screening were not designed to test specifically for miRNAs located in the brain and thus included a large number of miRNAs derived from other tissues. This is probably the reason for the 465 undetectable miRNAs in CSF and microdialysate. Regarding miRNAs detected solely in CSF and not in microdialysate, the molecular weight of a miRNA is around $6.5 \mathrm{kDa}$, but there is evidence that miRNAs acquire their extracellular stability from association in microvesicles / exosomes or by forming a ribonucleoprotein complex with Argonaute2, thus achieving protection against degradation by RNases [13,14,17]. Microvesicles have a diameter of $100-1000 \mathrm{~nm}$, exosomes have a diameter of $30-100 \mathrm{~nm}$, and Argonaute2 alone has a molecular weight of $96 \mathrm{kDa}$ [17]. The microdialysis membranes used in the present study allows molecules with a size up to respectively $20 \mathrm{kDa}$ and $100 \mathrm{kDa}$ to pass through. Thus, microvesicles, exosomes and Argonaute2bound miRNAs should not be able to pass through the membrane. By using differential centrifugation and sizeexclusion chromatography, Arroyo et al. found miR-142$3 p,-146 b,-150,-193 a-5 p,-744$ and $-886-3 p$ to be predominantly vesicle bound and miR-15b, 30c, 32, -126 , and -191 to be at least in part vesicle-bound [13]. This is in agreement with data from our study, in which these miRNAs showed a low RR and none of the remaining

Table 3 Selected references reporting roles of miRNAs with a high relative recovery during cerebral microdialysis

\begin{tabular}{|c|c|c|c|c|}
\hline MiRNA & Author, year & Design/model & Tissue/material & Relation of miRNA to acute cerebral injury \\
\hline \multirow[t]{2}{*}{ miR-29b } & Shi et al, 2011 [7] & $\begin{array}{l}\text { A: } 90 \text { min of MCA occlusion } \\
\text { in rats (ischemia) }\end{array}$ & $\begin{array}{l}\text { A: Brain tissue } 24 \text { hours } \\
\text { after occlusion }\end{array}$ & $\begin{array}{l}\text { Increased miR expression }(A+B) \text {, repression of the } \\
\text { anti-apoptotic protein } B C I 2 L 2 \text {, and thereby } \\
\text { neuronal cell death }(B) \text {. }\end{array}$ \\
\hline & & $\begin{array}{l}\text { B: Oxygen-glucose deprivation } \\
\text { in cortical neuronal cell cultures } \\
\text { from rats. }\end{array}$ & B: Cell suspension & $\begin{array}{l}\text { Pre-treating neuronal cultures with miR-29b inhibitor } \\
\text { decreased neuronal cell death (B) }\end{array}$ \\
\hline \multirow[t]{3}{*}{ miR-34a } & Su et al, 2014 [16] & $\begin{array}{l}\text { A: } 15 \text { min of MCA occlusion } \\
\text { in mice (preconditioning) }\end{array}$ & $\begin{array}{l}\text { A: Microglia extracted } \\
\text { ex vivo after } 3 \text { days }\end{array}$ & $\begin{array}{l}\text { MiR promotes CNS inflammation in microglia by } \\
\text { suppressing transcription of the twist } 2 \text { gene and } \\
\text { thereby the anti-inflammatory gene cMaf. }\end{array}$ \\
\hline & & B: Microglia cell culture from mice & B: Cell suspension & Induced by expression of p53. \\
\hline & Truettner et al, 2013 [15] & $\begin{array}{l}\text { Stretch injury, cortical neuron } \\
\text { cultures from rats }\end{array}$ & Cell suspension & $\begin{array}{l}\text { MiR promotes apoptosis by inhibiting translation } \\
\text { of the anti-apoptotic proteins } \mathrm{BCl} 2 \text { and XIAP and } \\
\text { increasing expression of the apoptotic cytokine } \\
\text { Caspase } 11 \text {. }\end{array}$ \\
\hline \multirow[t]{4}{*}{ miR-155 } & Su et al, 2014 [16] & $\begin{array}{l}\text { A: } 15 \text { min of MCA occlusion } \\
\text { in mice. (preconditioning) }\end{array}$ & $\begin{array}{l}\text { A: Microglia extracted } \\
\text { ex vivo after } 3 \text { days }\end{array}$ & $\begin{array}{l}\text { Increased miR expression (A) MiR promotes CNS } \\
\text { inflammation in microglia by suppressing the } \\
\text { anti-inflammatory gene cMaf in microglia }(A+B)\end{array}$ \\
\hline & & $\begin{array}{l}\text { B: Microglial cell culture } \\
\text { from mice }\end{array}$ & B: Cell suspension & $\begin{array}{l}\text { Normal cytokine induced expression of miR-155 } \\
\text { is suppressed in p53-deficient microglia (B). }\end{array}$ \\
\hline & & & & $\begin{array}{l}\text { Following treatment with INF- } \gamma \text {, the normal } \\
\text { expression of IL-1a and IL-1 } \beta \text { are suppressed in } \\
\text { miR-155 knock out microglia cell cultures (B). }\end{array}$ \\
\hline & Freilich et al, 2013 [19] & $\begin{array}{l}\text { LPS stimulation, microglial } \\
\text { cell cultures from mice pups }\end{array}$ & Cell suspension & $\begin{array}{l}\text { Increased miR expression after LPS and thereby } \\
\text { activation of several pro-inflammatory pathways. }\end{array}$ \\
\hline
\end{tabular}


predominantly vesicle-bound miRNAs were found in the group showing a high RR (Figures 2 and 3). Equally important, the above-mentioned vesicle-bound miRNA appeared to pass through the membrane when present as isolated RNA alone, i.e. without vesicle constituents or proteins (Figure 3-1A and Additional file 1). Furthermore, the observation that some miRNAs exhibit a high RR suggests that they exist at least partly in the free form in CSF, or that molecules smaller than Argonaute2 act as carriers in this medium.

The study has limitations regarding design and leaves room for further investigation. First of all, the in vitro study incubation at $37^{\circ} \mathrm{C}$ lasted on average 7 hours longer for samples used for microdialysis than for its identical reference samples. MiRNAs are considered stable in CSF at room temperature [18], but we cannot exclude that a fraction of miRNAs in the sample of total RNA from human brain, isolated from the constituents mediating RNase resistance, was degraded during this incubation period. Still, this would tend to reduce, rather than increase, the concentrations of miRNA in the in vitro microdialysate.

Secondly, as miRNA-profiling is still resource demanding, these studies are based on small sample sizes from few patients. We chose this approach in order to validate as many miRNAs as possible. Increasing reproducibility by increasing sample size would either increase costs significantly or we would have to measure only a few miRNAs. Likewise, we chose only to validate the in vitro data from screenings of 754 specific miRNAs with screenings of the 377 most common miRNAs (Human Pools A v.2.1) as the recovery results for these miRNAs could be extrapolated to the 377 miRNAs that were omitted (Human Pools B v.3.0).

Finally, we observed that miRNAs showed a higher RR through the membrane with a cut-off value of $20 \mathrm{kDa}$ than with a cut-off value of $100 \mathrm{kDa}$. We speculate that the human albumin solution used as perfusion fluid for the microdialysis catheter, with a membrane cut-off value of $100 \mathrm{kDa}$, may have reduced the RR of miRNAs, either by repelling them or by somehow contributing to their degradation. At any rate, we found no indication of an increased $R R$ of miRNA using a membrane with a cut-off value of $100 \mathrm{kDa}$ which is why the remaining studies of miRNA in microdialysis was done using the $20 \mathrm{kDa}$ membrane.

\section{Conclusions}

We have identified a group of miRNAs that show a high relative recovery during microdialysis both in vitro and in a clinical setting. In the future, it may be relevant to study local changes in specific miRNAs in relation to brain tissue oxygen tension, cerebral metabolites and continuous electroencephalography as well as the clinical course of the patient.

\section{Additional files}

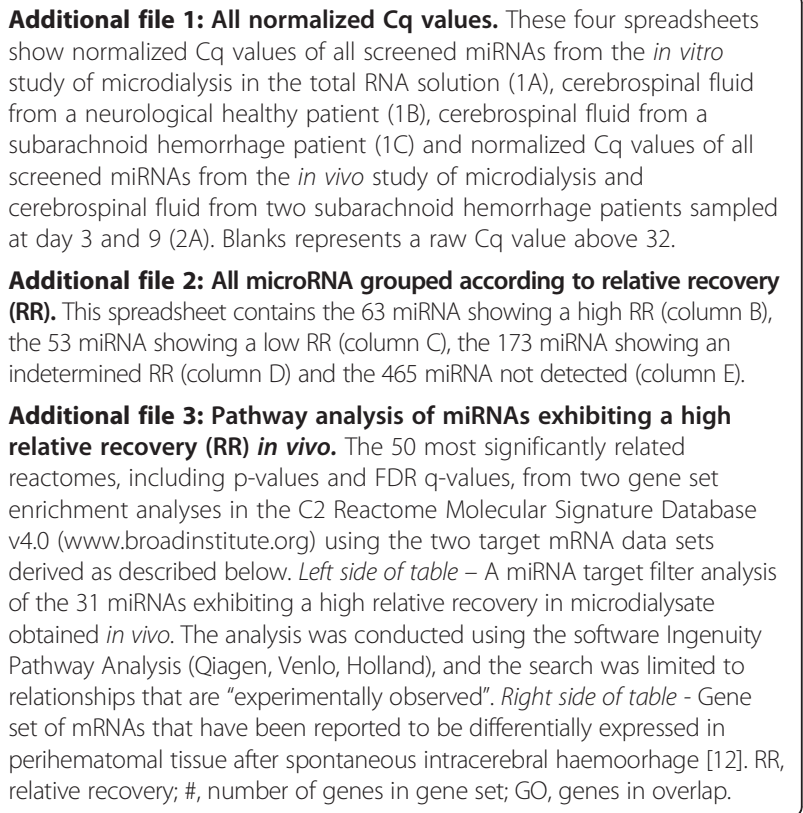

\section{Competing interests}

The authors declare that they have no competing interests.

\section{Authors' contributions}

SB designed the study, included the patients and collected in vivo samples, performed all in vitro studies, analysed data and drafted the manuscript. RR designed the original in vivo study, included patients and collected in vivo samples. MR analysed data and drafted the manuscript. LFH coordinated and designed the study and analysed the data. $\mathrm{NRH}$ designed the study. MJ interpreted the data. FCN conceived, designed and coordinated the study and drafted the manuscript. KM conceived, designed and coordinated the study and drafted the manuscript. All authors revised the manuscript critically and approved it in its final form.

\section{Acknowledgements}

Ms. Ewa Futoma from Centre for Genomic Medicine is gratefully acknowledged for her thorough teaching and supervision of SB in the necessary laboratory skills regarding RNA isolation and qRT-PCR. Dr. Søren Nielsen from Centre of Inflammation and Metabolism is gratefully acknowledged for his qualified introduction of SB to pre-processing and normalization of qRT-PCR data. Rigshospitalet's Board of Research, the Lundbeck Foundation, Brødrene Hartmanns Fond and Grosserer Jakob Ehrenreich \& Hustru Grethe Ehrenreichs Fond funded this study.

\section{Author details}

${ }^{1}$ Department of Neuroanaesthesiology, The Neuroscience Centre, Copenhagen University Hospital, Copenhagen, Denmark. ²Department of Neurosurgery, The Neuroscience Centre, Rigshospitalet, Copenhagen University Hospital, Copenhagen, Denmark. ${ }^{3}$ Centre for Genomic Medicine, The Diagnostic Centre, Rigshospitalet, Copenhagen University Hospital, Copenhagen, Denmark. ${ }^{4}$ Present address: Department of Clinical Biochemistry, Naestved Sygehus, Naestved, Denmark.

Received: 5 January 2015 Accepted: 24 April 2015 Published online: 07 May 2015

\section{References}

1. Vergouwen MD, Vermeulen M, van Gijn J, Rinkel GJ, Wijdicks EF, Muizelaar AD, et al. Definition of delayed cerebral ischemia after aneurysmal subarachnoid hemorrhage as an outcome event in clinical trials and observational studies: proposal of a multidisciplinary research group. Stroke. 2010;41:2391-5. 
2. Samuelsson C, Hillered L, Zetterling M, Enblad P, Ryttlefors, Hesselager G, et al. Cerebral glutamine and glutamate levels in relation to compromised energy metabolism: a microdialysis study in subarachnoid hemorrhage patients. J Cereb Blood Flow Metab. 2007;27:1309-17.

3. Zielke HR, Zielke CL, Baab PJ. Direct measurement of oxidative metabolism in the living brain by microdialysis: a review. J Neurochem. 2009;109 Suppl 1:24-9.

4. Saugstad JA. MicroRNAs as effectors of brain function with roles in ischemia and injury, neuroprotection, and neurodegeneration. J Cereb Blood Flow Metab. 2010;30:1564-76.

5. Cortez MA, Bueso-Ramos C, Ferdin J, Lopez-Berestein G, Sood AK, Calin GA. MicroRNAs in body fluids-the mix of hormones and biomarkers. Nat Rev Clin Oncol. 2011:8:467-77.

6. Cui H, Yang L. Analysis of microRNA expression detected by microarray of the cerebral cortex after hypoxic-ischemic brain injury. J Craniofac Surg. 2013;24:2147-52.

7. Shi G, Liu Y, Liu T, Yan W, Liu X, Wang Y, et al. Upregulated miR-29b promotes neuronal cell death by inhibiting Bcl2L2 after ischemic brain injury. Exp Brain Res. 2012;216:225-30.

8. Kim JM, Lee ST, Chu K, Jung KH, Kim JH, Yu JS, et al. Inhibition of Let7C MicroRNA is neuroprotective in a Rat intracerebral hemorrhage model. PLoS One. 2014;9:e97946.

9. Redell JB, Moore AN, Ward III NH, Hergenroeder GW, Dash PK. Human traumatic brain injury alters plasma microRNA levels. J Neurotrauma. 2010;27:2147-56.

10. Hillman J, Aneman O, Anderson C, Sjogren F, Saberg C, Mellergard P. A microdialysis technique for routine measurement of macromolecules in the injured human brain. Neurosurgery. 2005;56:1264-8.

11. Mestdagh P, Van VP, De WA, Muth D, Westermann F, Speleman F, et al. A novel and universal method for microRNA RT-qPCR data normalization. Genome Biol. 2009;10:R64.

12. Rosell A, Vilalta A, Garcia-Berrocoso T, Fernandez-Cadenas I, Domingues-Montanari S, Cuadrado E, et al. Brain perihematoma genomic profile following spontaneous human intracerebral hemorrhage. PLoS One. 2011;6:e16750.

13. Arroyo JD, Chevillet JR, Kroh EM, Ruf IK, Pritchard CC, Gibson DF, et al. Argonaute2 complexes carry a population of circulating microRNAs independent of vesicles in human plasma. Proc Natl Acad Sci U S A. 2011;108:5003-8

14. Wang K, Zhang S, Weber J, Baxter D, Galas DJ. Export of microRNAs and microRNA-protective protein by mammalian cells. Nucleic Acids Res. 2010;38:7248-59.

15. Truettner JS, Alonso OF, Bramlett HM, Dietrich WD. Therapeutic hypothermia alters microRNA responses to traumatic brain injury in rats. J Cereb Blood Flow Metab. 2011;31:1897-907.

16. Su W, Hopkins S, Nesser NK, Sopher B, Silvestroni A, Ammanuel S, et al. The p53 transcription factor modulates microglia behavior through microRNA-dependent regulation of c-Maf. J Immunol. 2014;192:358-66.

17. Turchinovich A, Weiz L, Langheinz A, Burwinkel B. Characterization of extracellular circulating microRNA. Nucleic Acids Res. 2011;39:7223-33.

18. Baraniskin A, Kuhnhenn J, Schlegel U, Chan A, Deckert M, Gold R, et al. Identification of microRNAs in the cerebrospinal fluid as marker for primary diffuse large B-cell lymphoma of the central nervous system. Blood. 2011;117:3140-6.

19. Freilich RW, Woodbury ME, Ikezu T. Integrated expression profiles of mRNA and miRNA in polarized primary murine microglia. PLoS One. 2013;8:e79416.

\section{Submit your next manuscript to BioMed Central and take full advantage of:}

- Convenient online submission

- Thorough peer review

- No space constraints or color figure charges

- Immediate publication on acceptance

- Inclusion in PubMed, CAS, Scopus and Google Scholar

- Research which is freely available for redistribution 